\title{
Projected changes in components of the hydrological cycle in French river basins during the 21st century
}

\author{
J. Boé, ${ }^{1,2}$ L. Terray, ${ }^{1}$ E. Martin, ${ }^{3}$ and F. Habets ${ }^{4}$ \\ Received 10 September 2008; revised 6 March 2009; accepted 20 May 2009; published 19 August 2009.
}

[1] The main objective of this paper is to study the impacts of climate change on the hydrological cycle of the main French river basins, including the different uncertainties at stake. In particular, the relative importance of modeling uncertainty versus that of downscaling uncertainty is investigated. An ensemble of climate scenarios are statistically downscaled in order to force a hydrometeorological model over France. Then, the main changes in different variables of the hydrological cycle are studied. Despite large uncertainties linked to climate models, some robust signals already appear in the middle of the 21 st century. In particular, a decrease in mean discharges in summer and fall, a decrease in soil moisture, and a decrease in snow cover, especially pronounced at the low and intermediate altitudes, are simulated. The low flows become more frequent but generally weak, and uncertain changes in the intensity of high flows are simulated. To evaluate downscaling uncertainties and assess the robustness of the results obtained with the statistical downscaling method, two other downscaling approaches are used. The first one is a dynamical downscaling methodology based on a variable resolution atmospheric model, with a quantile-quantile bias correction of the model variables. The second approach is based on the so-called anomaly method, that simply consists of perturbing present climate observations by the climatological change simulated by global climate models. After hydrological modeling, some discrepancies exist among the results from the different downscaling methods. However they remain limited and to a large extent smaller than climate model uncertainties, which raises important methodological considerations.

Citation: Boé, J., L. Terray, E. Martin, and F. Habets (2009), Projected changes in components of the hydrological cycle in French river basins during the 21st century, Water Resour. Res., 45, W08426, doi:10.1029/2008WR007437.

\section{Introduction}

[2] The fourth report of the Intergovernmental Panel on Climate Change (IPCC) shows that Europe is likely to undergo strong climatic changes in response to anthropogenic forcing, characterized in particular by large changes of the hydrological cycle [Meehl et al., 2007a; Christensen et al., 2007]. Indeed, the state-of-the-art coupled AtmosphericOceanic General Circulation Models (AOGCM) simulations from the World Climate Research Programme's (WRCP) Coupled Model Intercomparison Project phase 3 (CMIP3) multimodel data set [Meehl et al., 2007b], realized in the context of the IPCC Assessment Report 4 (AR4), generally show an increase of precipitation over northern Europe, and a decrease over southern Europe and the Mediterranean. The latitude where the sign of precipitation anomalies changes evolves during the year and is maximum in the

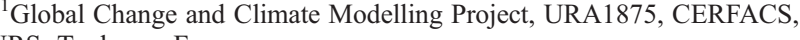
CNRS, Toulouse, France.

${ }^{2}$ Now at Department of Atmospheric and Oceanic Sciences, UCLA, Los Angeles, California, USA.

${ }^{3}$ Groupe d'études de l'Atmosphère Météorologique, Centre National de Recherches Météorologiques, Météo-France, CNRS, Toulouse, France.

${ }^{4}$ Centre de Géosciences, Équipe SHR, UMR Sisyphe 7619, ENSMP, Fontainebleau, France.
}

Copyright 2009 by the American Geophysical Union. 0043-1397/09/2008WR007437 north during summer and minimum in the south during winter [Giorgi and Coppola, 2007]. Over southern and central Europe, the largest changes in precipitation, and probably the most worrying, occur during summer, with for example a decrease in precipitation larger than $20 \%$ in ensemble mean over France, at the end of the 21 st century using a moderate emission scenario [Christensen et al., 2007]. This decrease in precipitation is accompanied by a large increase in surface temperature. These results suggest that important changes in water resources might occur in southern and central Europe, with potential large impacts on agriculture, ecosystems, and economy.

[3] The detailed situation is however more complex than the one depicted by the general picture previously introduced. Precipitation anomalies vary strongly among the different CMIP3 models and even the sign of precipitation change is not clear over large portions of Europe during some seasons, especially in the transition zone between the northern positive anomaly and the southern negative one. The latitude of this transition zone may vary by a few hundred kilometers among the climate models. Moreover, given the poor representation of the topography in most of the CMIP3 models due to a relatively low resolution, its location may not be very accurate. These limitations may have deep implications when it comes to predicting the impacts of climate change on the hydrological cycle at the 
country scale. France is located in the transition zone during most of the year and is thus particularly affected by the uncertainties in the evolution of the hydrological cycle under anthropogenic forcing.

[4] The results of global climate models therefore suggest that it is important to quantify the impacts of climate change on the continental hydrological cycle in France and evaluate the associated uncertainties. This is, however, a complex scientific question, and two major difficulties arise. First, when it comes to studying the impacts of climate change, the relevant spatial scales for the physical processes involved and from the practical point of view of policymaking decisions are much smaller than the ones that AOGCMs are currently able to treat. An intermediary step, called downscaling, is thus necessary to derive from the global climate models regional climate scenarios at the relevant spatial scales for the impact study. Second, studying the impacts of climate change involves a large number of uncertainties. The main steps necessary to evaluate the impacts of climate change can be summarized as follows: (1) construction of emission and/or concentration scenario; (2) global climate modeling; (3) downscaling; (4) impact modeling. Step 1 involves serious economical/sociological uncertainties. Step 2 and step 4 are associated with physical and numerical uncertainties, whereas the downscaling step 3 is associated with important methodological issues. Step 2 includes here both epistemic (linked to biases in the model representation of the climate system) and natural variability uncertainty.

[5] These different uncertainties add up, which may result in major uncertainties in the final results of the impact study. These uncertainties may not necessarily prevent the practical use of the conclusions of an impact study for decisionmaking purpose, but only if they are recognized, correctly treated, and acknowledged. From a practical point of view, effective strategies must therefore be designed to best treat the different uncertainties, but it is a difficult task given the numerous practical issues that may arise in this type of study.

[6] The main goal of this paper is to develop and apply a relevant methodology to study the impacts of climate change on the hydrological cycle in the main French river basins, with a special focus on the different uncertainties involved. In particular, we focus on the effect of climate models and downscaling uncertainties (steps 2 and 3 previously mentioned) on simulated hydrological variables.

[7] Most of our study is focused on the 2046-2065 period, where the influence of the emission scenario and its associated uncertainties still remain relatively weak. For example, in the 2046-2065 period, the Special Report on Emissions Scenarios A1B and A2 scenarios and projected global temperature change are still rather similar [Meehl et al., 2007a]. This period is chosen as we want to focus on the relatively near future to better meet the societal needs: the 20462065 period is the nearest period for which the necessary daily data are available in the CMIP3 archive.

[8] In this paper, the uncertainties associated with the impact model (i.e., here, a hydrological model) are not treated. Sufficiently realistic hydrological models for presentday conditions are expected to simulate rather consistent responses to climate change. But even if hydrological modeling introduces some non-negligible uncertainties, it is logical from a methodological point of view to first focus on the upstream uncertainties before dealing with the ones involved in the last step of the study. Future work will combine upstream uncertainties with the uncertainties linked to hydrological modeling.

[9] To address the uncertainties associated with step 2, a large ensemble of climate models from the CMIP3 archive is studied. This implies that it is necessary to downscale many climate projections, which has some practical implications concerning the choice of the downscaling method. These methods are generally divided in two families [Mearns et al., 1999]. Statistical downscaling (SD) consists of building an empirical relationship based on observations or pseudo-observations between large-scale atmospheric predictors and the local variables necessary as input to the impact model [Wilby et al., 1998]. Then the large-scale predictors from the climate models are used to derive the high-resolution climate scenarios on the basis of this empirical relationship. A wide variety of SD methods exist, as described by Wilby et al. [2004] and Haylock et al. [2006]. The main advantage of SD is that it is computationally inexpensive so that it can be applied to a large ensemble of climate models. The main theoretical issue with SD is that it is based on a partial empirical relation derived in the present climate that may miss important physical processes occurring in the future climate.

[10] The second approach, dynamical downscaling (DD), is based on the use of a Regional Climate Model (RCM), forced at the boundaries by results from a low-resolution climate model, to increase the spatial resolution over a given area of interest [Giorgi et al., 1990]. The RCMs are physically based models able to capture most of the processes occurring in the changing climate. From this point of view, they may be more accurate than a SD approach. However, despite their high resolution, RCMs still have important biases that must be corrected before forcing the impact model, in order to obtain satisfactory results. The problem is that this bias correction step involves the same kind of assumption as SD: a correction function is computed comparing RCM results to the observations in the present climate and then is applied to correct the future regional projections. This present-day bias correction function may not necessarily remain valid in the future climate. A second issue with DD is that it is computationally expensive. Therefore, it is difficult to obtain a large ensemble of regional climate scenarios with a dynamical downscaling method.

[11] In this paper, we use a SD method as the main downscaling tool because we need to downscale a large number of climate projections. However, given the weaknesses of the SD mentioned earlier, two alternative approaches are also used, in order to test the robustness of our results to the choice of the downscaling method. It will also give an idea of the uncertainties associated with the downscaling step compared to the uncertainties associated with global climate models. One of these alternative downscaling approach is based on a variable resolution atmospheric model with a high resolution over Europe and a quantile-quantile bias correction method. The other approach is a very simple and widely used one that uses the climatological anomalies computed from the AOGCM to perturb the observed variables necessary to force the impact 


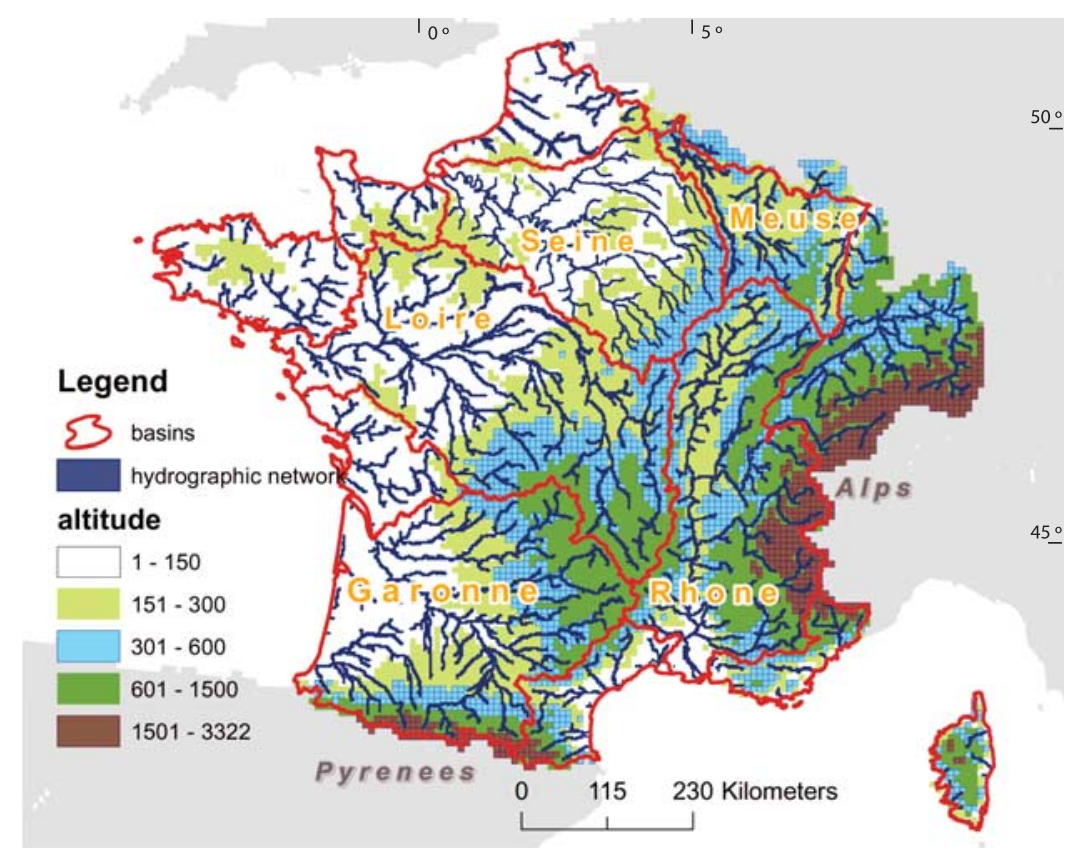

Figure 1. Topography and hydrographic network.

model. In this paper, we will conventionally characterize the climate change signal by the ensemble mean of the different climate models and the uncertainty by the intermodel spread.

[12] This paper is divided as follows. In section 2, we describe the downscaling methodologies, the climate models, and the hydrometeorological model used in the study. In section 3 we analyze the results obtained with the statistical downscaling approach and address the question of the uncertainties linked to climate models. In section 4 we address the question of the uncertainties linked to the choice of the downscaling method. Finally, in section 5, we discuss the main conclusions of our study concerning the impacts of climate change on the hydrological cycle in France and the main general methodological insights gained from this study.

\section{Models and Methods}

\subsection{Climate Models}

[13] We study the impacts of climate change on the hydrological cycle in France using two sets of coupled climate model integrations from the WRCP CMIP3 multimodel data set archive, realized in the context of the IPCC AR4 and compiled by the Program for Climate Model Diagnosis and Intercomparison (PCMDI) of Lawrence Livermore Laboratory [Meehl et al., 2007b]. The first set (" $20 \mathrm{c} 3 \mathrm{~m}$ ") are 20th century climate simulations, and the second set ("sreasa1b") uses the SRES-A1B emission scenario. Given the availability of the variables necessary for this study, the following models are used: (1) CGCM3.1(T63); (2) CNRM-CM3; (3) CSIROMk3.0; (4) GFDL-CM2.0; (5) GFDL-CM2.1; (6) GISSAOM; (7) GISS-ER; (8) IPSL-CM4; (9) MIROC3.2(medres); (10) ECHO-G; (11) ECHAM5/MPI-OM; (12) MRICGCM2.3.2; (13) INGV-SXG; (14) CCSM3. Two main periods are considered in the following: 1971-2000 and 2046-2065.

\subsection{Hydrometeorological System}

[14] To simulate the evolution of the continental hydrological cycle in France in response to anthropogenic forcing, the SAFRAN-ISBA-MODCOU (SIM) hydrometeorological coupled system is used. A complete description and validation of SIM is given by Habets et al. [2008]. SIM is the combination of three independent systems. SAFRAN [Durand et al., 1993] analyzes the seven low-level atmospheric variables at the hourly time step on a $8 \mathrm{~km}$ grid needed by the soil-vegetation-atmosphere transfer (SVAT) scheme ISBA. The seven variables are liquid and solid precipitation, incoming long-wave and short-wave radiation fluxes, $10 \mathrm{~m}$ wind speed, $2 \mathrm{~m}$ specific humidity, and temperature. A description and validation of the SAFRAN data set is given by Quintana Segui et al. [2008].

[15] The SAFRAN analysis is based on all available observations collected by Météo-France and the operational analyses of the weather prediction model of Météo-France and some climatological data. ISBA [Noilhan and Planton, 1989] computes the surface water and energy budgets. Then MODCOU [Ledoux et al., 1984] routes the surface runoff simulated by ISBA in the hydrographic network and computes the evolution of the aquifers. Figure 1 shows the topography of the study area as given by the SAFRAN grid and the French hydrographic network. To study the impact of climate changes on the hydrological cycle, the SAFRAN data set is replaced by equivalent (i.e., same time step, resolution, and variables) high-resolution climate scenarios derived using three different downscaling methods.

\subsection{Dynamical Downscaling With Quantile/Quantile Bias Correction}

[16] We use the Météo-France Action de Recherche Petite Echelle Grande Echelle (ARPEGE) global Atmospheric General Circulation Model (AGCM) [Déqué et al., 1994] in a variable resolution configuration [Gibelin and Déqué, 2003] in order to downscale the global coupled climate 
model CNRM-CM3 from the CMIP3 archive. The variable resolution allows a high resolution of $50-60 \mathrm{~km}$ over the domain of interest to be obtained. Sea surface temperatures from CNRM-CM3 have been used to force ARPEGE, after the removing of mean monthly climatological biases. This simulation is named ARP-VR in the following. The 19502100 period is simulated, using the SRES-A1B scenario in the 21 st century and observed forcing during the 20th century. The variables from ARP-VR necessary to force ISBA-MODCOU are first interpolated on the SAFRAN grid and then corrected using a quantile-quantile mapping technique [Déqué, 2007] as described by Boé et al. [2007]. This method is intended to correct the statistical distribution of the simulated variables in a nonparametric way. Correction increments for each centile of the model variable are computed by comparing the empirical cumulative probability distribution function (cpdf) of the simulated variable to the corresponding SAFRAN cpdf on the same present climate period. Then, the correction increments are used to correct the simulated variable in the future climate. The ARP-VR simulation is also statistically downscaled with the SD method described in the section 2.4 in order to evaluate the differences of the two downscaling approaches when the same climate model is used.

\subsection{Statistical Downscaling Method}

[17] The SD method used in this study is an evolution of the method described by Boé et al. [2006] for the Seine basin and tested concerning the simulation of river discharges in the present climate in the work of Boé et al. [2007]. The main principles of the method remain identical, but some modifications have been made in order to downscale the forcing variables over the whole French territory (and the adjacent areas necessary to simulate river discharges in France). Two atmospheric predictors are used in this SD scheme: sea level pressure (SLP) and surface temperature averaged over western Europe. The SAFRAN data set previously described provides the pseudo-observed local variables in the learning period. The atmospheric predictors for the learning period are extracted from the NCEP reanalysis. Given the availability of the SAFRAN analysis at the time of this study, the learning period is 1981-2005.

[18] The SD method is based on weather typing and conditional resampling of the days of the learning period. First of all, the three main steps involved in the development of the SD method during the learning period are described. First, weather types based on SLP and discriminating for French precipitation are extracted as in the work of Boé and Terray [2008a], using an automatic partitioning algorithm and taking into account precipitation properties during the classification process. The four seasons are treated separately, and between 9 and 10 weather types are obtained depending on the season. The second step is intended to represent the within-type variability of precipitation. Indeed, it is important to take into account the dynamical variability within the weather types to better represent the variability of precipitation [Boé and Terray, 2008a]. There is generally a strong link between the distance of the SLP pattern of a given day to the weather types and the intensity of precipitation. In order to take this effect into account, several multivariate regressions are used. The predictors are the daily Euclidean distances between the SLP pattern of a given day and the weather types of the corresponding season. For each regression, the predictand is the root mean square of daily precipitation averaged over a given area: to facilitate some diagnoses of validation not shown in this paper, the 220 grid points of the ARPEGE model over the region of interest are used to define these precipitation indices. These 220 regressions allow 220 daily precipitation indices over France, that only depend on the large-scale circulation, to be computed. Note that in the work of Boé et al. [2006], as the precipitation is rather homogeneous on the Seine basin, a single precipitation index was defined. It is not possible to make this assumption when considering the entire French territory, which explains why more indices are used here. The results of the study are, however, not very sensitive to the precise choice of the number and repartition of the precipitation indices. Surface temperature is used as a secondary predictor in the downscaling algorithm: a daily temperature index is finally computed as the average of NCEP temperature over western Europe.

[19] Once the SD scheme has been developed on the learning period, it is possible to downscale each day $D$ of a climate projection, given the SLP and surface temperature fields simulated by the climate model.

[20] 1. Given its SLP pattern, the day $D$ is classified in the nearest weather type established on the learning period.

[21] 2. The 220 values of the precipitation indices corresponding to the day $D$ are computed on the basis of the distances of its SLP pattern to the weather types and on the regression coefficients computed on the learning period.

[22] 3. The average temperature over western Europe of the climate model for the day $D$ is computed.

[23] 4. The final step of the downscaling algorithm consists of conditional resampling of the days of the learning period, by searching for the day of the learning period in the same weather type with the closest precipitation and temperature indices. Once this day has been found, the corresponding 24 hourly values of the seven spatially distributed variables of the SAFRAN analysis are used to force the hydrometeorological model for the day $D$. However, the temperature of the chosen day in the learning period is not always sufficient to represent the future temperature anomaly of the day $D$ simulated by the climate model. In this case, a correction of the SAFRAN temperature for the chosen day is applied before forcing the hydrometeorological model. This correction is only applied when the difference of temperature between the value of the temperature index of the day $D$ simulated by the climate model and used as predictor and the temperature of the chosen day in the present climate in the same geographical area is greater than $2 \mathrm{~K}$. The partition between snow and precipitation and the long-wave radiation are modified as described by Etchevers et al [2002] in order to be consistent with the modified temperature. The method described in this section is used to downscale the 14 CMIP3 models and the ARP-VR simulation previously described in the present and future climate.

\subsection{Anomaly Method With CMIP3 Models Outputs}

[24] One of the simplest and most widely used downscaling method is the so-called anomaly or perturbation method. It consists of superposing to a high-resolution observed data set the mean climatological anomaly due to 
Table 1. Synthesis of the Hydrological Projections With Associated Downscaling Methodologies

\begin{tabular}{|c|c|}
\hline Name & Meteorological Forcing \\
\hline CMIP3 Stat. & $\begin{array}{l}14 \text { hydrological projections: statistical downscaling } \\
\text { of } 14 \text { climate models in the } 1971-2000 \\
\text { and } 2046-2065 \text { periods. }\end{array}$ \\
\hline CMIP3 ano. & $\begin{array}{l}1 \text { hydrological projection: anomaly method, } \\
\text { with monthly anomalies computed between } \\
\text { the } 2046-2065 \text { and } 1971-2000 \text { periods, } \\
\text { as the ensemble mean of the } 14 \text { climate models. }\end{array}$ \\
\hline ARP Dyn. & $\begin{array}{l}1 \text { hydrological projection: quantile-quantile } \\
\text { correction of the ARP-VR variable resolution model. } \\
\text { Period } 1950-2100 \text {. }\end{array}$ \\
\hline ARP Stat. & $\begin{array}{l}1 \text { hydrological projection: statistical downscaling } \\
\text { of the ARP-VR variable resolution model. } \\
\text { Period } 1950-2100 \text {. }\end{array}$ \\
\hline
\end{tabular}

climate change estimated using climate models. The perturbed meteorological forcing obtained is then used to force the impact model. This method is easy to implement and can be directly used with low-resolution climate simulations. However, when a global climate model is used, the regional climate change signal may not be correctly captured given the intrinsic limitations due to the low resolution of these models. Moreover, with this method, only the mean climatological change in the atmospheric variables is taken into account. The temporal variability and statistical distribution are assumed not to change in the future climate, which is a strong assumption. This method therefore only allows the effects of mean climate change signal on the impact variable to be taken into account: changes in extremes directly caused by changes in the mean are taken into account, but those resulting from a modification of the shape of the statistical distribution of the climate variables are not. This method is therefore not suitable to study the changes in extremes and the variability of the impact variable, which may be major components of the impacts of climate change. The anomaly method is implemented as described by Etchevers et al. [2002], using monthly anomalies. The climatological anomalies are computed for each month as the difference between the 2046-2065 and 19712000 periods. Then, the ensemble mean of the climatological anomalies in the 14 CMIP3 models is computed for each month and added to the hourly historical SAFRAN data separately for each month.

[25] As the anomalies of the atmospheric variables are estimated using the ensemble mean of the CMIP3 models, it allows us to extract an estimate of the climate change signal and then to simulate its impact on the river discharges, using a single hydrometeorological simulation. The different hydrological projections done with the ISBA-MODCOU hydrometeorological system are summarized in Table 1.

\subsection{Elements of Validation}

[26] In order to illustrate the general ability of the different downscaling approaches to represent regional climate properties properly, several control hydrological simulations in present day are done. The seasonal cycle of the simulated discharges of the four main French rivers are then compared to observations (OBS) (Figure 2). In the first simulation (CTRL), the forcing variables come from the SAFRAN data set. In the second one (NCEP Stat.), the

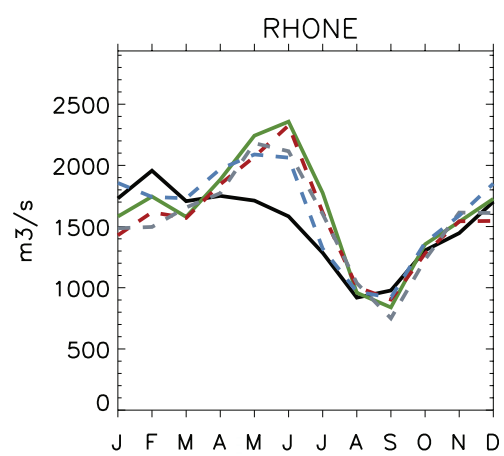

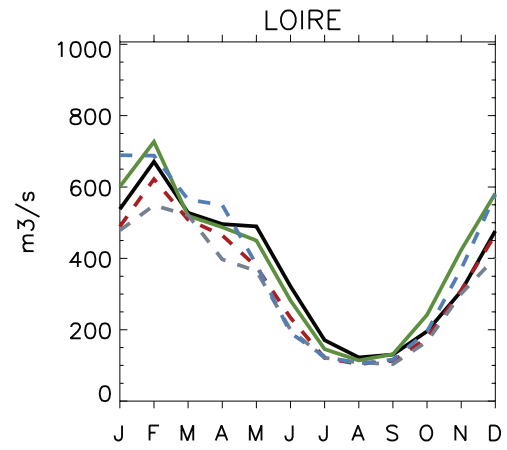
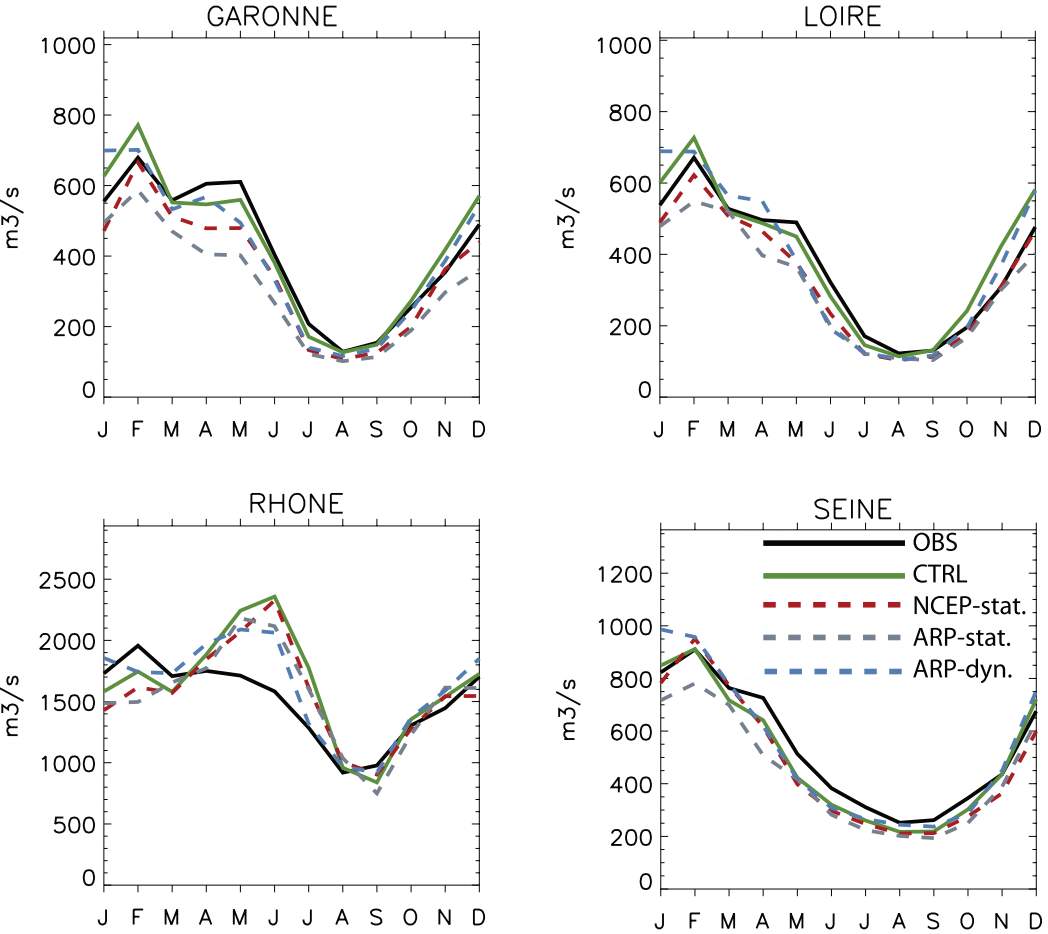

Figure 2. Climatological seasonal cycle of river discharges $\left(\mathrm{m}^{3} / \mathrm{s}\right)$ on the $1971-1999$ period as observed (OBS), as simulated by SAFRAN-ISBA-MODCOU (CTRL), and as simulated by ISBAMODCOU forced by the SD of the NCEP reanalysis (NCEP Stat.), the SD of ARP-VR (ARP Stat.), and ARP-VR after quantile-quantile bias correction (ARP Dyn.). River discharges are shown for the Garonne at Lamagistère, the Loire at Blois, the Rhône at Viviers, and the Seine at Poses. 


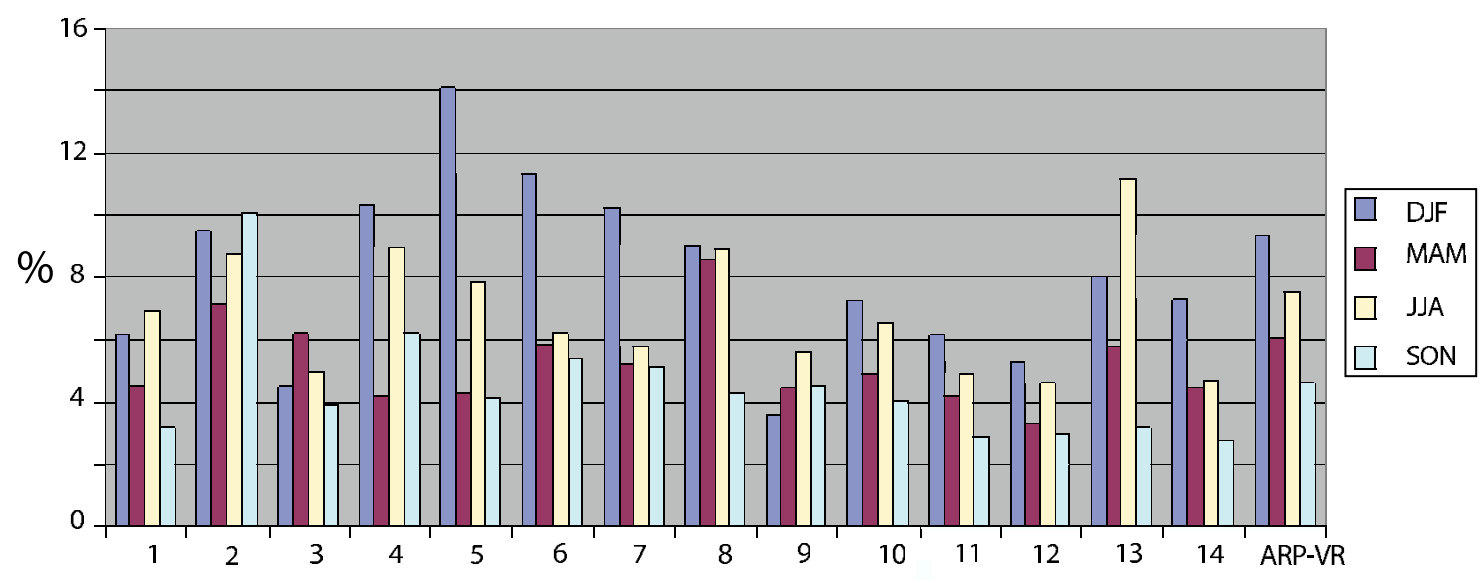

Figure 3. Climatological area-averaged absolute relative error in downscaled precipitation (\%) for the different climate models, computed for each season. SAFRAN precipitation are used as reference. The absolute relative errors in precipitation climatology are computed for each grid point and then averaged.

forcing variables are obtained through the statistical downscaling of the NCEP reanalysis. Note that a cross-validation procedure has been used to downscale NCEP reanalysis: for each downscaled day, the 15 previous days and the 15 following days are removed from the possible resampling pool in the learning period. Note that a thorough validation of SAFRAN-ISBA-MODCOU is given by Habets et al. [2008], and a validation and comparison of the SD and DD methods in the present climate for the Seine basin is given by Boé et al. [2007]. As said previously, the SD method used in this previous study was slightly different, but its performances are very similar with the performances of the extended SD method used in this paper.

[27] The NCEP hydrological simulation allows testing of the SD method when high-quality predictors are used. The comparison of the NCEP simulation to the CTRL simulation provides a direct measure of the skill of the SD method. The third simulation (ARP Stat.) is forced by the results of the statistical downscaling of ARP-VR, and the fourth simulation (ARP Dyn.) uses as forcing the variables simulated by ARP-VR and corrected with the quantile-quantile bias correction algorithm. Note that the results obtained with ARP Stat. are representative of the results obtained with the CMIP3 models.

[28] Compared to observations, SAFRAN-ISBA-MODCOU generally simulates realistic river discharges. However, for the Rhône, and the Garonne in a lesser extent, some important discrepancies between OBS and CTRL are seen. They are mainly linked to the presence of dams on these basins that are not taken into account by ISBA-MODCOU.

[29] The discharges of NCEP Stat. are very similar to the discharges of CTRL, showing the intrinsic skill of the SD method, when realistic predictors are used. When the predictors used for SD come from ARP-VR, a small degradation of the results is seen compared to NCEP Stat. It is especially true for the Garonne in winter. These discrepancies arise from the biases in the predictors (SLP and surface temperature) simulated ARP-VR. However, the results of ARP Stat. are globally realistic. As expected, the results of ARP Dyn. are very similar to the ones of CTRL, as by construction, the forcing variables obtained after bias correction have the same statistical distribution as SAFRAN variables. These results show that globally the SD and DD approaches used in this study allows realistic river discharges to be obtained after hydrological modeling.

[30] Note that even if it is critical that the downscaling methods allow realistic river discharges to be obtained after hydrological modeling during the historical period, the realism of hydrological projections obtained under anthropogenic forcing with a given downscaling method may not be directly linked to the realism of simulated present-day river discharges obtained with this method. Indeed, a downscaling method may lead to very realistic simulated discharges in the present climate but nevertheless be unsuitable in the future climate. It is the case, for example, if some important processes under anthropogenic forcing are not taken into account in the downscaling method.

[31] As simulated river discharges may mask compensating errors in the input meteorological variables, in Figure 3 we show a validation diagnostic directly computed on downscaled precipitation for each climate model, precipitation being the most important and difficult variable to downscale in our study. The climatological absolute errors in precipitation depend on the season and climate models, but they are generally limited and most of the time smaller than $10 \%$. Therefore, large-scale predictors from climate models are sufficiently well simulated by the climate models to allow realistic precipitation after downscaling to be obtained.

\section{Results of the Multimodel Study Based on Statistical Downscaling}

[32] This section is focused on the results obtained in a multiple climate model framework using the SD approach. The 14 CMIP3 models have been statistically downscaled for the periods $1971-2000$ and 2046-2065. The 28 corresponding hydrometeorological simulations with the ISBA-MODCOU hydrometeorological model have been done (CMIP3 Stat.). In this section, we summarize the main impacts of climate change on the hydrological cycle of French river basins. A particular attention is given to the uncertainties linked to the global climate models. 


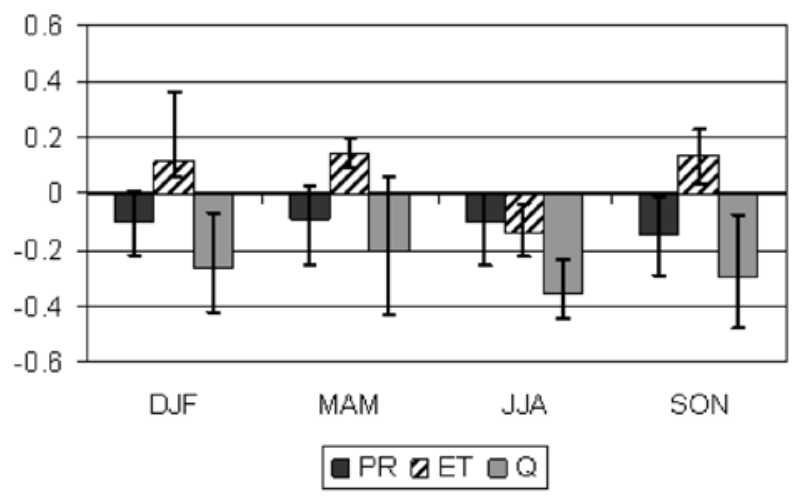

GARONNE

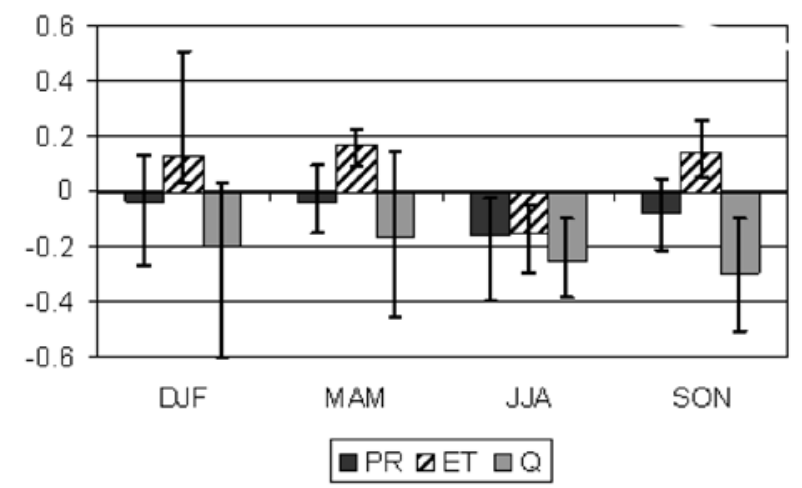

SEINE
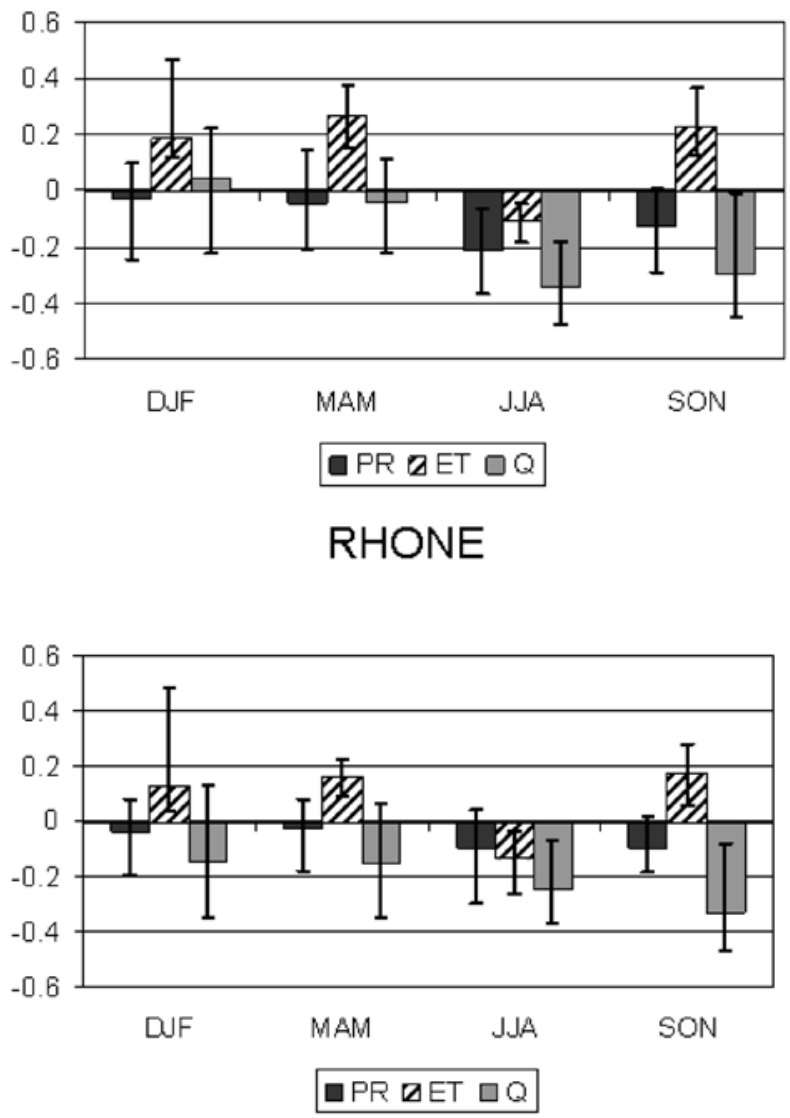

LOIRE

Figure 4. Relative changes (without units) in precipitation (PR), evapotranspiration (ET), and river discharges at the outlet $(Q)$ in the four main French river basins between the periods 2046-2065 and 1971-2000. The length of the large bar stands for the multimodel average, while the whiskers stand for the minimum and maximum values among the 14 climate models.

\subsection{Mean Changes}

[33] First, the mean relative changes in the main variables of the continental hydrological cycle (downscaled precipitation, evapotranspiration, and discharges simulated by ISBA-MODCOU) in the four principal French river basins (Rhône, Loire, Seine, and Adour-Garonne, simply Garonne hereafter) are computed and analyzed (Figure 4). The changes in downscaled precipitation are generally rather limited compared to the changes in evapotranspiration and river discharges. The largest changes in precipitation occur in summer and autumn, with decreases between $10 \%$ and $30 \%$ in ensemble mean, depending on the basins. The sign of the changes in summer and autumn downscaled precipitation is consistent among the climate models. In winter and spring the changes in ensemble-mean precipitation are more limited, and the consistency of the sign of the changes among the climate models is weak, except in the Garonne basin, where precipitation exhibits a $10 \%$ decrease in ensemble mean.

[34] The changes in evapotranspiration (ET) exhibit the same seasonal pattern in the four basins, with an increase in winter, spring, and autumn and a decrease during summer. Even with lower precipitation in winter and spring, the climatological availability of moisture in the soil remains large in the future climate. ET may therefore increase, as the energy available at the surface increases in the future climate because of anthropogenic forcing and climate feedbacks. As a result of this increase in ET and small changes in precipitation, the soil moisture progressively decreases during winter and spring (as shown later in Figure 10) and becomes limited at the beginning of summer. As precipitation decreases during summer, this hydric stress leads to a decrease of ET during this season, even if more energy would be available for ET in the future climate. This general mechanism likely to affect midlatitudes has been described in pioneering climate studies [Manabe et al., 1992] but has been discussed since then [Seneviratne et al., 2002]. Boé and Terray [2008b] show that direct results of some but not all CMIP3 model simulations exhibit such a behavior of summer drying over central Europe, including France. It is thus interesting to note that after statistical downscaling and hydrological modeling, this behavior is seen for all the climate models used in this study. Note that the climatology of downscaled precipitation is generally far less biased than the climatology of the precipitation directly simulated by the CMIP3 models, which may partly explains the greatest consistency among the model responses after downscaling and hydrological modeling. Moreover, the validation of the SAFRAN-ISBA-MODCOU system by Habets et al. [2008] 

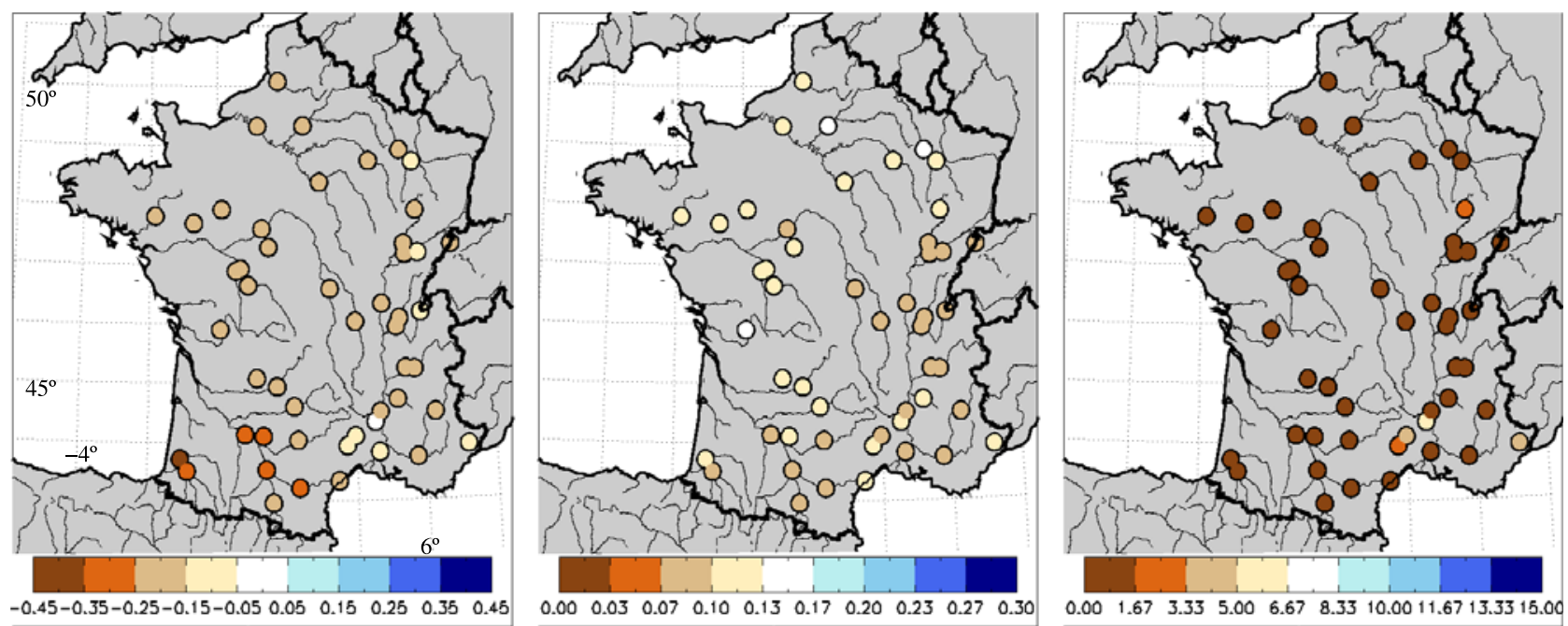

Figure 5. (left) Multimodel annual relative changes in river discharges between the periods 2046-2065 and 1971-2000. (middle) Intermodel standard deviation of relative changes in river flows. (right) Number of models (out of 14) giving an increase of discharges.

gives confidence in the evapotranspiration simulated by this system, and therefore in the changes in evapotranspiration simulated in the future climate. It is then worth noting that the unrealistic increase in ET directly simulated by some CMIP3 models over central Europe and France is likely to lead to an underestimation of temperature increase in summer. As we use temperature as a predictor in our SD model, this could have an effect on the results of our study. This example illustrates how possible biases in climate model processes may have an impact on a downscaling study.

[35] Concerning river discharges, a large decrease affects all basins in summer and autumn, with changes between $-20 \%$ and $-40 \%$. This decrease is consistent among all downscaled models. In winter and spring, the picture is less clear. Except for the Rhône, discharges decrease in ensemble mean, but some downscaled models give an increase of discharges after hydrometeorological modeling. The decrease of discharges in winter is more pronounced for the Garonne, because of a non-negligible decrease of precipitation. Concerning the Rhône, the changes of discharges are weakly positive in winter and negative in spring, but the sign of the response varies among the models, and it is not possible to draw robust conclusions. For the Rhône basin, the change in river discharges is largely influenced by changes of the repartition between solid and liquid precipitation in winter over the Alps and by snowmelt. The intermodel spread in temperature changes therefore plays an important role.

[36] The results shown in Figure 4 indicate that even with limited precipitation changes at the middle of the $21 \mathrm{st}$ century, important changes in other hydrological variables may occur, with possible strong impacts on society. Another important result of Figure 4 is that the uncertainties linked to climate models (shown by error bars) are large, concerning all aspects of simulated hydrological changes.

[37] The geographical distribution of changes in river discharges are shown in Figure 5, a map of the relative annual changes in discharges for selected gauging stations in France. At the annual level, the decrease is generalized with values close to $-20 \%$. The changes in southwestern France (mainly the Garonne basin) are slightly greater $(-30 \%)$, mainly because of the specific decrease of precipitation in winter in this region, but overall, the spatial variability of changes in discharges is rather limited. More details about changes in southwestern France will be given in the following. The intermodel spread measured by one standard deviation is large, between $7 \%$ and $17 \%$, but the consistency of the sign of the changes is strong over the whole country.

[38] Figure 6 shows the relative annual changes in river discharges averaged over France for each climate model. The changes vary from $-5 \%$ to $-33 \%$ between the models. Figure 6 illustrates the high level of uncertainties in river discharges associated with climate models.

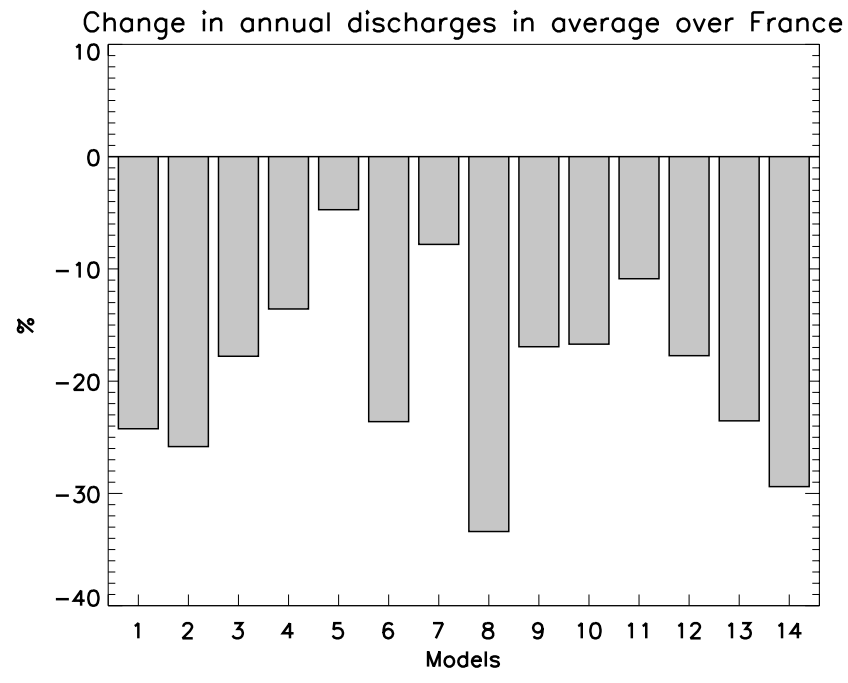

Figure 6. Annual relative changes in river discharges between the 2046-2065 and 1971-2000 periods averaged over France for each individual CMIP3 climate model. 

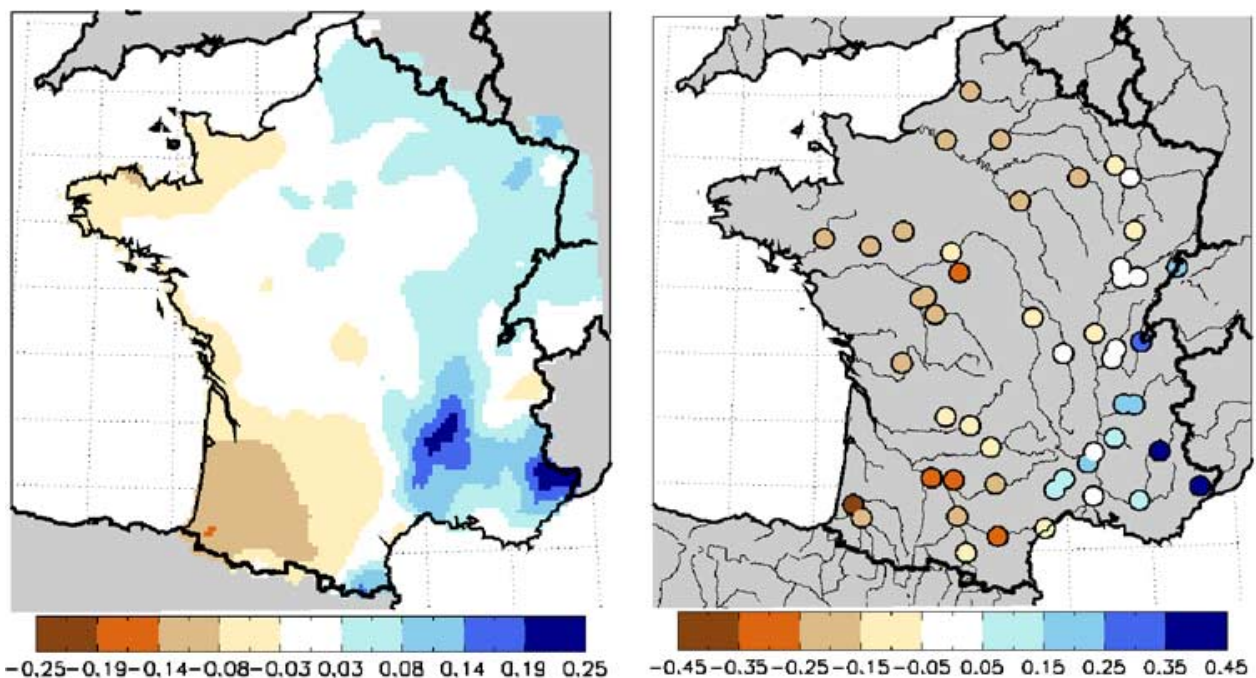

Figure 7. Relative changes in (left) multimodel precipitation and (right) river discharges in winter between 2046-2065 and 1971-2000.

\subsection{Case of Winter}

[39] The winter season is especially interesting as it illustrates nicely the utility of downscaling, as discussed in this section. It is also the only season which shows a widespread increase in river discharges, in southeastern France (Figure 7, right). This increase of discharges is partly due to an increase of precipitation (Figure 7, left) but also to an increase of the ratio between liquid precipitation and solid precipitation over the Alps (not shown). From a practical point of view, the change in the seasonality of river discharges that results from the change in the ratio between solid and liquid precipitation (increase of discharges in winter and decrease in spring or early summer) may have some important impacts.

[40] Both the changes in precipitation and discharges exhibit a strong contrast between southwestern and southeastern France in winter. The increase in precipitation in southeastern France is accompanied by a decrease in precipitation over southwestern France. To understand this small-scale spatial pattern, Figure 8 depicts the ensemble mean changes in sea level pressure and wind over Europe, simulated by the CMIP3 models. An increase of pressure over the Mediterranean Sea is seen, leading to more southerly flows over southern France. This change in atmospheric circulation interacts with the relief and leads to a decrease of precipitation in southwestern France due to the effect of the Pyrenees mountain range and to an increase in southeastern France, mainly on the relief (south of Massif Central and Alps).

[41] The spatial pattern of precipitation changes obtained here after statistical downscaling, based on the large-scale circulation from the CMIP3 models, is not directly captured by the CMIP3 models [see Christensen et al., 2007]. It is probably due to their poor representation of the relief given their low resolution. At the typical horizontal resolution of a CMIP3 model, i.e., around $200 \mathrm{~km}$, the Pyrenees and the Massif Central mountain ranges are either very unrealistic or missing. Therefore, low-resolution climate models cannot correctly represent the effect of the increase of southerly flows on precipitation in southern France, as it is strongly relief-dependent. Downscaling is necessary to capture the effect of changes in circulation on precipitation in this area, which has some important implications concerning changes in the hydrological cycle of the Garonne and Rhône basins.

\subsection{Changes in Extreme Indicators}

[42] Changes in the temporal variability and extremes of the hydrological cycle may be more important from the point of view of the impacts than changes of the mean. However, it is more challenging to deal with the former than the latter. Compared to simple approaches, like the anomaly method previously described, the SD approach allows changes in the temporal variability of the impact variables

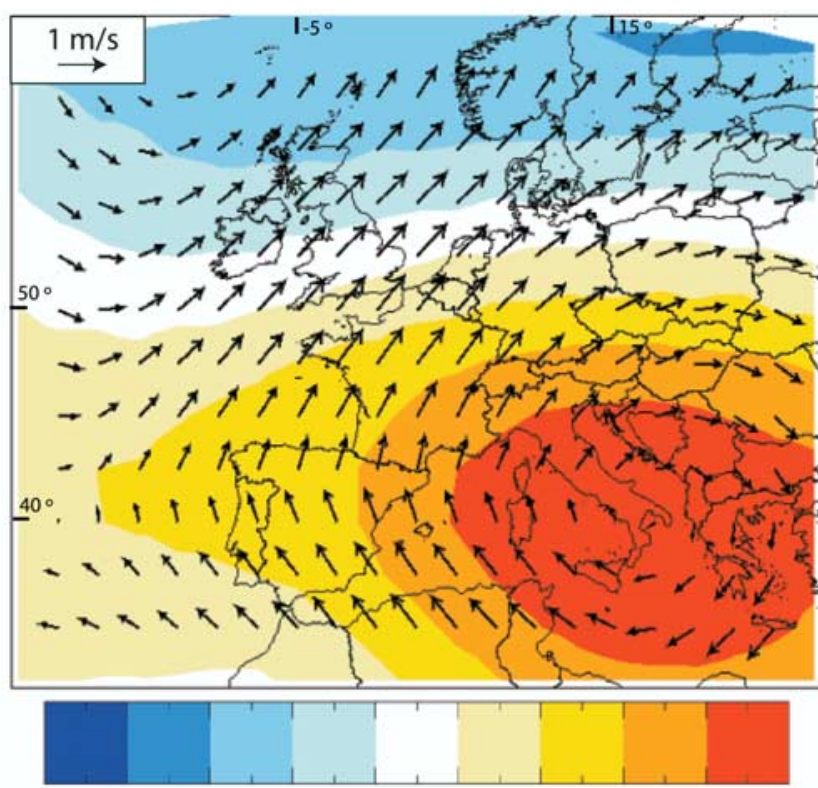

$-1.80-1.40-1.00-0.60-0.200 .20 \quad 0.601 .001 .401 .80$

Figure 8. Multimodel change in mean sea level pressure (hPa) and wind (m/s) between 2046-2065 and 1971-2000. 

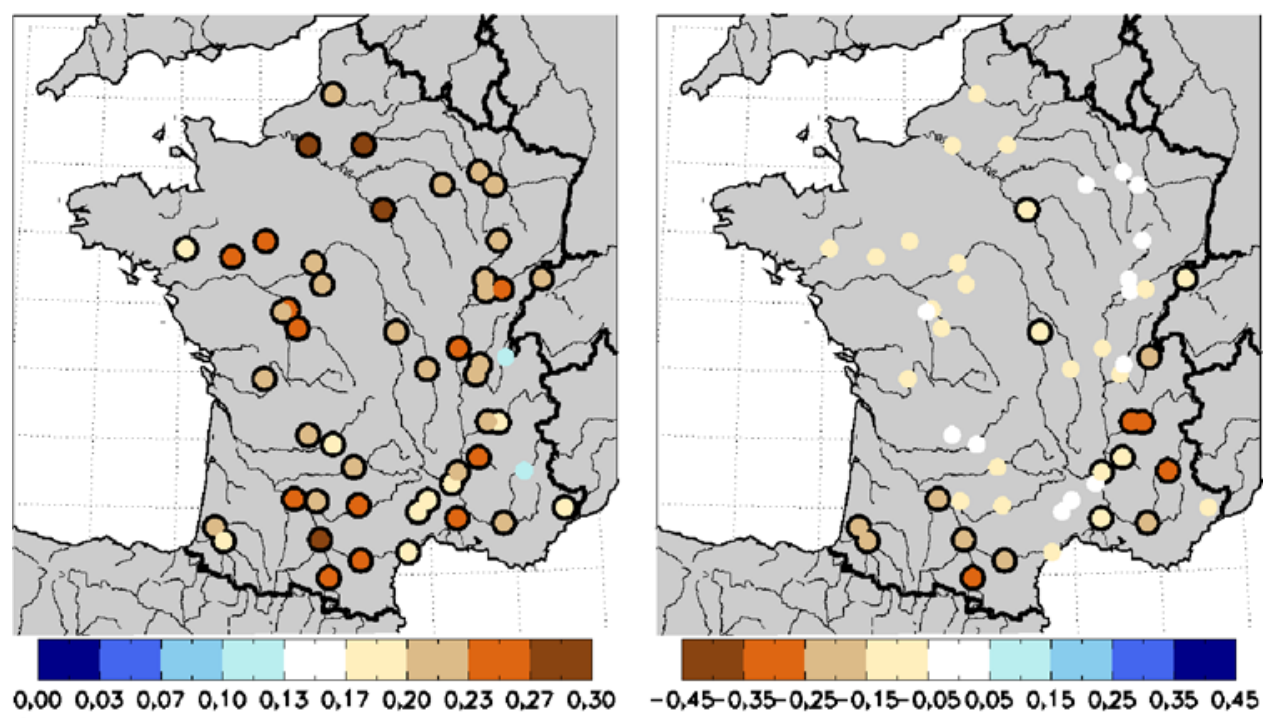

Figure 9. (left) Ensemble mean of the percentage of days in the 2046-2065 period with a discharge lower than the first decile of daily discharges computed on the control period. (right) Ratio of the 90th quantile of daily discharges between future and present climate. In the two cases, the black circles indicate the station where a consistency in the sign of the change exists among (at least $70 \%$ of the models with the same sign.)

to be studied. Given the length of the simulations and the inherent limitations of SD methods based on conditional resampling, we cannot deal with changes in real hydrological extremes, as, for example, centennial floods. Nevertheless, we can adopt the conventional and simple approach based on climate extreme indicators in order to provide useful information concerning changes in extremes.

[43] Figure 9 (left) shows the percentage of days in the future climate with a discharge lower than the first decile of present-day daily discharges. For the great majority of gauging stations, a value greater than $20 \%$ is seen, indicating that the frequency of occurrence of low flows is more than doubled in the future climate. The sign of the changes in low-flow occurrence is consistent among the different climate models except for two stations in the Alps.

[44] Figure 9 (right) shows the ratio of the 90th centile of daily discharges between future and present climate. The value of the 90th centile decreases over most of France in the future climate, but the decrease remains limited. It is therefore interesting to note that changes in the upper tail of the distribution are much smaller than the decrease in the mean previously shown (Figure 5). Climate change does not simply induce a shift of the mean, but also a modification of the shape of the statistical distribution. Except in southern France, there is no consistency of sign among the changes simulated by the different models. Over northern France, it is thus possible that an increase in high-flow intensity occurs in parallel with an increase in low-flow frequency and a decrease in mean discharges.

\subsection{Other Variables of the Hydrological Cycle}

[45] Regarding the continental hydrological cycle, climate change may have important impacts not only on river discharges but also on other variables like soil moisture or snow cover. Given the decrease in precipitation and the increase in evapotranspiration during most of the year and in particular in spring, soil moisture undergoes large changes, with potential important impact for ecosystems and agriculture. Figure 10 shows the seasonal cycle of the soil wetness index (SWI) in the future and in the present climate, in average on two river basins (Seine in northern France and Garonne in southern France), representative of the changes in the whole country. These two basins are chosen as they are characterized by important agricultural activities. The SWI is defined as SWI $=\left(w_{\text {tot }}-w_{\text {wilt }}\right) /\left(w_{f c}-\right.$ $w_{\text {wilt }}$ ) where $w_{\text {tot }}$ is the volumetric water content of the soil column, $w_{f c}$ the field capacity, and $w_{\text {wilt }}$ the wilting point). It is a measure of the water available in the soil for the plants. A general decrease of the SWI is seen during all the months and is especially pronounced during spring. The intermodel spread largely increases in the future climate. The climatological minimum value of the SWI in the present climate that is reached around August in the two basins is reached around 1 month earlier in the future climate in ensemble mean and is exceeded from July to October. This may have
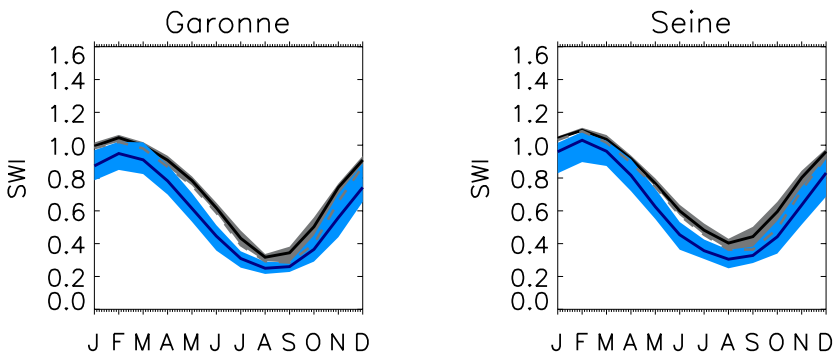

Figure 10. Seasonal cycle of the Soil Wetness Index in the present (gray and black) and future (blue) climate, averaged over the Seine basin and the Garonne basin. The line gives the ensemble mean, while the shaded areas correspond to the intermodel spread given by one standard deviation. 

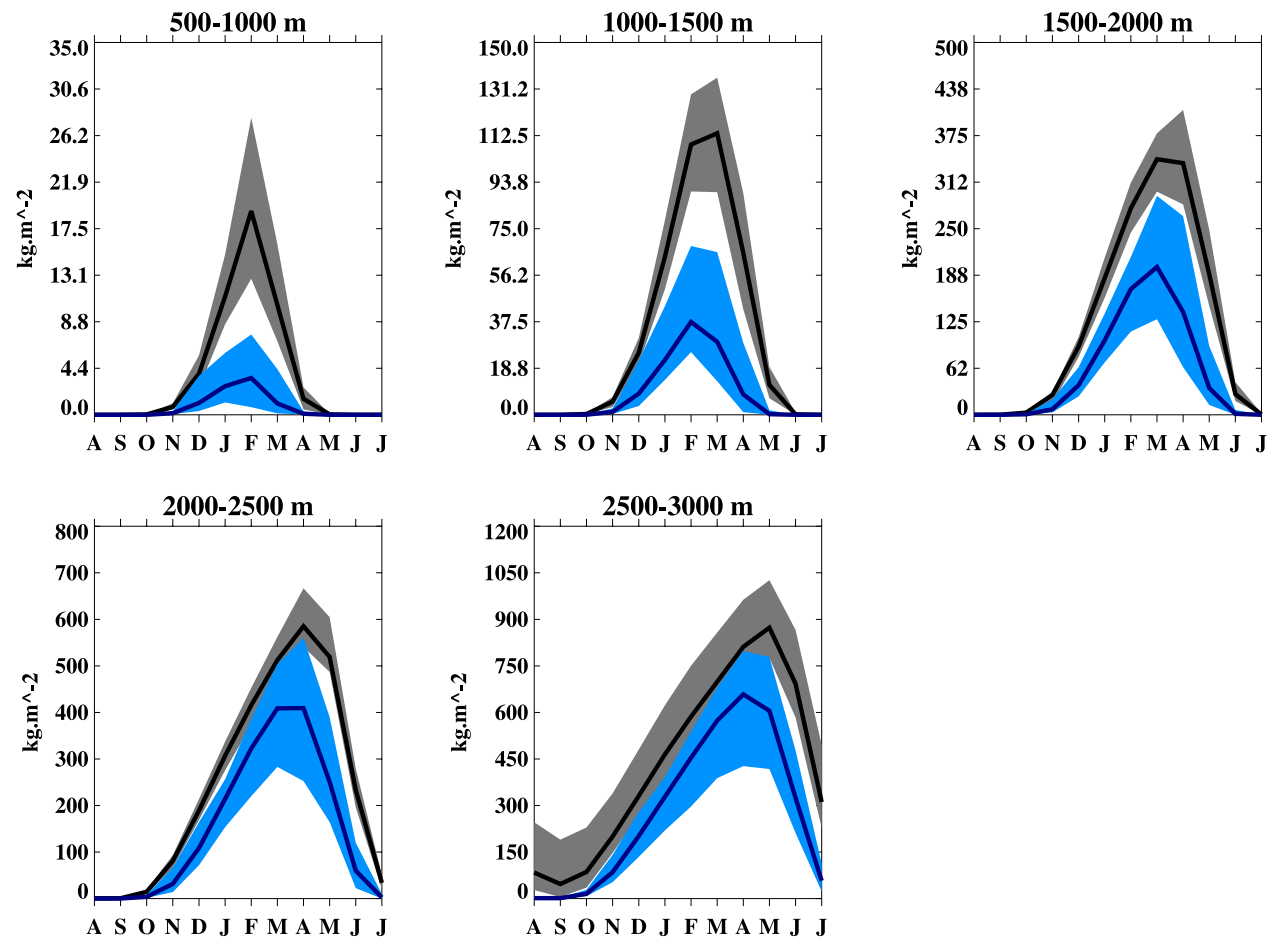

Figure 11. Seasonal cycle of the snow water equivalent $\left(\mathrm{kg} \mathrm{m} \mathrm{m}^{-2}\right)$ in the present (gray and black) and future (blue) climate in the Alps, by altitude ranges. The line gives the ensemble mean, while the shaded areas correspond to the intermodel spread given by one standard deviation.

serious implications for agriculture, and in particular irrigation procedures.

[46] Another variable potentially very sensitive to climate change is snow cover. Figure 11 shows for the Alps the present and future seasonal cycle of the snowpack (snow water equivalent) for different altitude ranges. Even if some models simulate an increase in snowfall in some parts of the Alps (not shown), the decrease in snowpack is quasigeneralized. The decrease in relative value is particularly pronounced at low and intermediate altitudes, while a large decrease in absolute value is seen above $1500 \mathrm{~m}$. Above $2000 \mathrm{~m}$, the maximum of snow water equivalent is shifted 1 month earlier than in the present climate. A similar pattern of changes is simulated for the other mountain ranges in France (not shown).

\section{Uncertainties Associated With Downscaling}

[47] In section 3, we saw that important uncertainties in the evolution of the hydrological cycle in France are linked to climate models. In this section, we evaluate the role of downscaling methods on the uncertainties in hydrological projections. All the results previously shown are based on a SD method. As explained in section 1, the main theoretical weakness of SD is that it is necessary to make the hypothesis that the empirical relation established in the present climate is still valid under anthropogenic forcing. Moreover, a SD is always based on a simplified representation of the real world processes and thus might not capture all the mechanisms involved in a changing climate.

[48] In order to reinforce our confidence in the results based on SD, it is important to compare the results obtained with the SD method previously described (CMIP3 Stat.) to those obtained using very different approaches. Here, we use the two alternative approaches previously described in section 2, the simple anomaly method (CMIP3 ano.) and a complete dynamical downscaling procedure, with bias correction, based on the ARPEGE variable resolution model (ARP Dyn.). Given the high computing cost of dynamical downscaling, it is applied to a single global climate model (CNRM-CM3). The SD method is also applied to ARP-VR (ARP Stat.) so that we can compare the results of the two methods both in the present and future climate, in a relevant way.

\subsection{Climatological Changes}

[49] Conventionally, we estimate in this paper the signal of climate change as the ensemble mean of the results obtained with different climate models, and the uncertainties as the intermodel spread. A major question is to what extent the signal of climate change in river discharges is affected by the choice of the downscaling methodology.

[50] To answer this question, we compare the estimate of the climate change signal in river discharges based on the SD approach (CMIP3 Stat.) described in section 3 and based on the anomaly method with the anomalies computed as the multimodel average of the variables directly simulated by the CMIP3 models (CMIP3 ano.). Even if only a single hydrological simulation is done for CMIP3 ano., this approach provides a multimodel estimate of the climate change signal on river discharges. Results are shown in Figure 12 .

[51] The main difference between CMIP3 ano. and CMIP3 Stat. is seen for the Garonne in winter. Indeed, the 

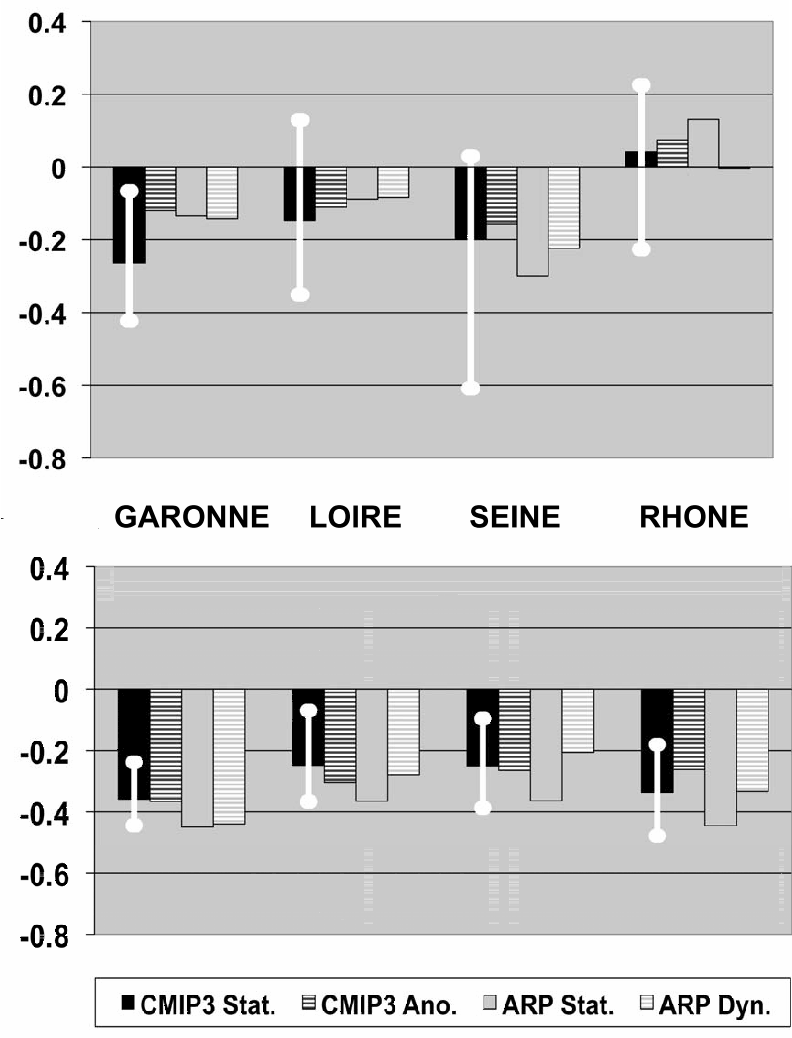

Figure 12. Relative changes in the discharges of the Garonne, Loire, Seine, and Rhône (without units) in winter and summer given by the anomaly method (CMIP3 ano.), the statistical downscaling method of the CMIP3 models (CMIP3 Stat.), ARP-VR after bias correction (ARP Dyn.), and the statistical downscaling of ARP-VR (ARP Stat.). The white error bar gives the intermodel spread (given by the minimum and maximum) of CMIP3 Stat.

decrease of CMIP3 Stat. in ensemble mean is more than twice greater than the decrease of CMIP3 ano. This is because of the interaction of the increase in southerly flow with the Pyrenees, that is poorly captured by the CMIP3 models, as previously explained (section 3.2). Except for this particular case, the results of the two approaches are generally similar, in the two seasons and for the four basins.

[52] It is also interesting to note that the differences between these two estimates of the climate change signal are always largely smaller than the range of the responses obtained using different climate models with the SD approach, that is indicated by the error bars in Figure 12. Indeed, the results obtained using two different climate models may largely diverge. The major conclusion here is that concerning the climate change signal, uncertainties associated with the downscaling methodology are limited.

[53] In a second time, the uncertainties linked to the downscaling methodology are quantified when looking at an individual model (ARP-VR). The results of ARP Stat. and ARP Dyn. are also shown in Figure 12. The results of the two downscaling approaches with ARP-VR are consistent in all seasons and basins. The differences between ARPEGE Stat. and ARPEGE Dyn. are, however, greater than the ones between CMIP3 Stat. and CMIP3 ano. It is probably due to the fact that in the multimodel estimates, the differences due to the downscaling method somewhat cancel out when the ensemble mean is computed. However, the differences between the two downscaling approaches with ARP-VR remain most of the time largely smaller than the uncertainty range due to the choice of the climate model with the SD approach.

[54] The results shown in Figure 12 therefore indicate that in our case, (1) the signal of climate change in river discharges is not very dependent on the downscaling approach; (2) it is dangerous to try to characterize the impacts of climate change on river discharges using only one or a few climate models; and (3) the changes in the hydrological cycle based on the SD of the 14 CMIP3 models shown in section 3 are robust.

\subsection{Temporal Evolution of Discharges Obtained With ARPEGE}

[55] As the results obtained with ARP-VR after bias correction or SD are relatively close to the multimodel climatological estimate (Figure 12) they may provide a relevant picture of the temporal evolution of river discharges. It is also interesting to compare the two downscaling methods on the whole 1950-2100 period. Here the comparison is made in terms of annual mean and high flows.

[56] Figure 13 shows the series of mean annual discharges for the Garonne, Loire, Seine, and Rhône. A reasonable agreement is seen in the simulated interannual and low-frequency variability using the two downscaling approaches. Interestingly, the decrease in river discharges mainly occurs in the 2010-2050 period, and a stabilization occurs in the second half of the 21 st century.

[57] Figure 14 shows the evolution of the annual maximum of daily discharges obtained with the two downscaling methods. No clear trend is seen, but a strong interannual and low-frequency variability exists. An increase in the interannual variability of the annual maximum during the second half of the 21 st century is visible for the Loire, but results are less clear for the other rivers. Note that for all rivers, the maximum of the 1950-1999 period can be exceeded in the future climate, even if the mean flows decrease. This result is consistent with those shown previously for the CMIP3 models (Figure 9): changes in discharge distributions are not symmetric, and high flows change much less than low and mean flows.

\section{Discussion and Conclusion}

[58] Even if large uncertainties remain about the evolution of the hydrological cycle of the main French river basins under anthropogenic climate change, some robust signals appear as soon as the middle of the 21 st century, using a moderate emission scenario. A decrease in river discharges at the annual level and during summer and fall is a robust feature obtained with most of the climate models. The different climate models also lead consistently to large negative changes in soil moisture (especially during spring) and in snow cover in the Alps. These results suggest that some serious issues concerning water resources and water management may affect France during this century. While water resources are likely to decrease, the need for water in some activities like agriculture may possibly increase, to 

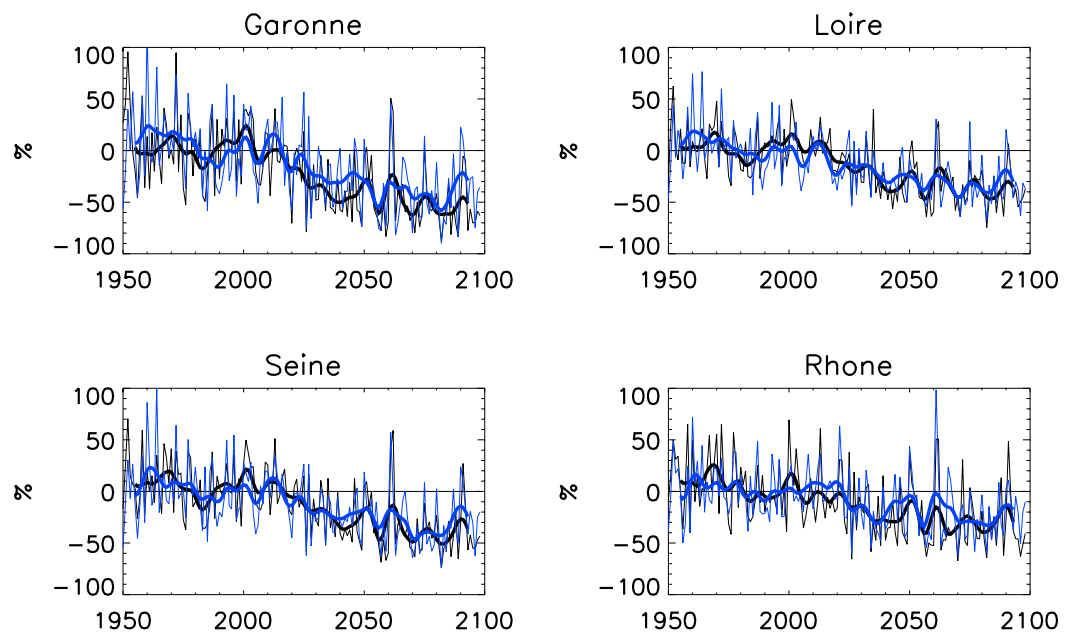

Figure 13. Mean annual river discharges in the 1950-2100 period, as relative anomaly compared to the 1971 - 1999 climatological value (\%), for the four main French river basins. Results are shown for ARPVR after quantile-quantile bias correction (black) and for the SD method applied to the same model (blue). The thick line is the smoothing of the interannual series.

compensate for summer drying, for example. It raises important concerns about the repartition of water among the different users.

[59] Climate change does not simply lead to a shift in the mean, but also in modifications of the whole statistical distribution of river discharges. While a large increase in the occurrence of low flows and a large decrease in mean flows is simulated, the changes in the intensity of high flows are very limited, despite the decrease in mean precipitation. It must be noted that changes in high flows might be intrinsically more uncertain because they are strongly linked to changes in extreme precipitation, whose evolution at the regional scale is hard to predict. The evolution of low and mean flows may be more dependent on mean precipitation and temperature changes, in which we have more confidence. Moreover, downscaling methods are generally less suitable when it comes to model and analyze extreme precipitation changes. These limitations apart, our results suggest that the negative impacts linked to a decrease in low and mean flow might not be balanced by a decrease in the negative impacts linked to flood occurrence.

[60] A weakness of this study is that a single hydrological model is used. Therefore, uncertainties linked to hydrological modeling are not taken into account. Even if the ability of the ISBA-MODCOU hydrological model to realistically simulate the present-day hydrological cycle [Habets et al., 2008] gives confidence in the results shown in this paper, ongoing work in the REXHYSS project will specifically address this issue.

[61] More general conclusions also emerge, concerning methodological issues associated with the study of the impacts of climate change. Compared to the perturbation
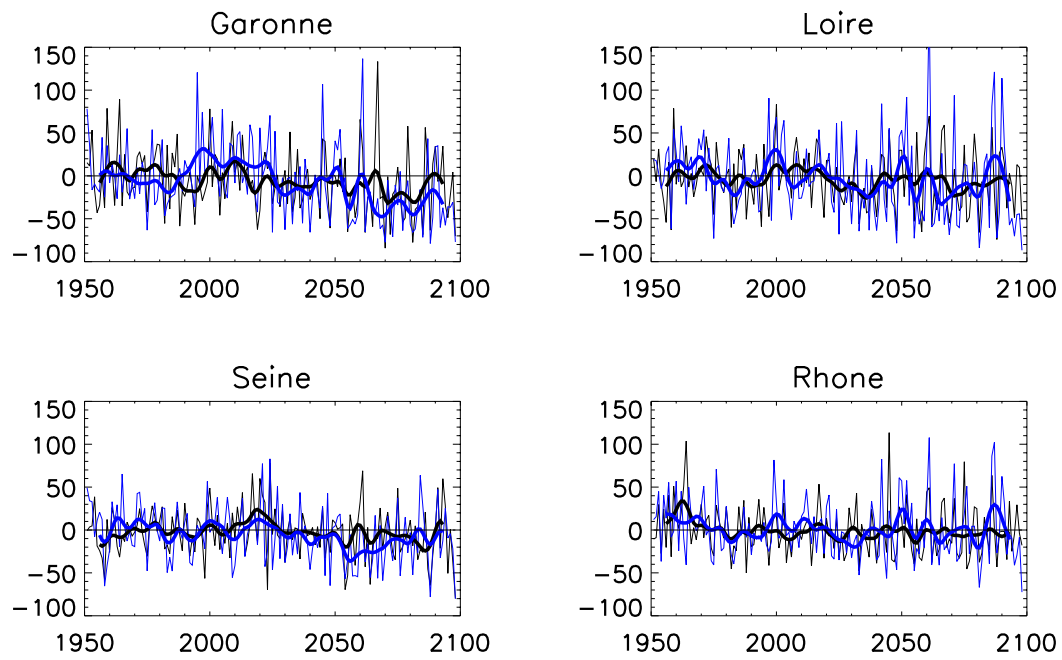

Figure 14. Annual maximum of daily flow in the 1950-2100 period, as relative anomaly compared to the 1971-1999 climatological value (\%) on the four main French river basins. Results are shown for the bias corrected ARP-VR (black) and for the SD method applied to the same model (blue). The thick line is the smoothing of the interannual series. 
method, an advantage of SD is that it allows the capture of the changes affecting the temporal variability and the statistical distribution of the forcing meteorological variables. We also showed that AOGCMs at the typical current resolution cannot capture local-scale changes involving the complex topography of southwestern France. Statistical downscaling and dynamical downscaling with bias correction have their own strengths and weaknesses and are complementary. One could argue that using a physical model with a complete representation of the important mechanisms that may play in the future climate is preferable. However, the bias correction necessary after dynamical downscaling is based, like $\mathrm{SD}$, on an empirical statistical relationship, established by comparing the present climate regional simulations to the observations. It is therefore necessary to make a stationarity assumption, similar to the $\mathrm{SD}$ one, stipulating that the correction function remains valid in the future climate. It may not be the case. From a practical point of view, the main difference between statistical and dynamical downscaling approaches is that SD methods can be easily applied to a large number of AOGCMs, which is more difficult using dynamical downscaling. As shown in this paper, a large ensemble of climate models are necessary to correctly characterize the signal of climate change in the continental hydrological cycle. In this context, the uncertainties linked to climate models are larger than the uncertainties linked to the choice of the downscaling method. It is therefore probably more appropriate to use a simple statistical downscaling method that allows a large number of models to be downscaled rather than to dynamically downscale a single climate model. However, the confrontation of the results obtained with statistical and dynamical downscaling, at least for a single climate model, is very useful to assess the robustness of the hydrological projections. Concerning the European region, the multiple RCM simulations driven by multiple AOGCMs done in the ENSEMBLES project will open new opportunities for the dynamical downscaling approach.

[62] The uncertainties linked to global climate models represent an important part of the total uncertainties that affect the results of an impact study. Moreover, to improve statistical downscaling or bias correction methods, a fine understanding of the physical mechanisms involved in anthropogenic climate change is needed. For these two reasons, it is very important to better understand the physical origin of the discrepancies between the results of the different climate models. This may in particular allow for better constraint of the response of the model given observational evidence, which is a necessary step to provide more reliable climate impacts projection to policy makers.

[63] Acknowledgments. We acknowledge the modeling groups, the Program for Climate Model Diagnosis and Intercomparison (PCMDI), and the WCRP's Working Group on Coupled Modelling (WGCM) for their roles in making available the WCRP CMIP3 multimodel data set. Support of this data set is provided by the Office of Science, U.S. Department of Energy. This work was supported in part by the GICC program of the French Ministry of ecology and sustainable development through the REXHYSS project.

\section{References}

Boé, J., and L. Terray (2008a), A weather-type approach to analyzing winter precipitation in France: twentieth-century trends and the role of anthropogenic forcing, J. Clim., 21, 3118-3133, doi:10.1175/2007JCLI1796.1.
Boé, J., and L. Terray (2008b), Uncertainties in summer evapotranspiration changes over Europe and implications for regional climate change, Geophys. Res. Lett., 35, L05702, doi:10.1029/2007GL032417.

Boé, J., L. Terray, F. Habets, and E. Martin (2006), A simple statisticaldynamical downscaling scheme based on weather types and conditional resampling, J. Geophys. Res., 111, D23106, doi:10.1029/ 2005JD006889.

Boé, J., L. Terray, F. Habets, and E. Martin (2007), Statistical and dynamical downscaling of the Seine basin climate for hydro-meteorological studies, Int. J. Clim., 27(12), 643-1655, doi:10.1002/joc.1602.

Christensen, J. H., et al. (2007), Regional climate projections, in Climate Change 2007: The Physical Science Basis. Contribution of Working Group I to the Fourth Assessment Report of the Intergovernmental Panel on Climate Change, edited by S. Solomon et al., Cambridge Univ. Press, Cambridge, U. K.

Déqué, M. (2007), Frequency of precipitation and temperature extremes over France in an anthropogenic scenario: Model results and statistical correction according to observed values, Global Planet. Change, 57, 16-26, doi:10.1016/j.gloplacha.2006.11.030.

Déqué, M., C. Dreveton, A. Braun, and D. Cariolle (1994), The climate version of the ARPEGE-IFS: a contribution of the French community climate modelling, Clim. Dyn., 10, 249-266.

Durand, Y., E. Brun, L. Merindol, G. Guyomarc'h, B. Lesaffre, and E. Martin (1993), A meteorological estimation of relevant parameters for snow schemes used with atmospheric models, Ann. Glaciol., 18, 65-71.

Etchevers, P. C. Golaz, F. Habets, and J. Noilhan (2002), Impact of a climate change on the Rhône river catchment hydrology, J. Geophys. Res., 107(D16), 4293, doi:10.1029/2001JD000490.

Gibelin, A.-L., and M. Déqué (2003), Anthropogenic climate change over the Mediterranean region simulated by a global variable resolution model, Clim. Dyn., 20, 327-339.

Giorgi, F., and E. Coppola (2007), European climate-change oscillation (ECO), Geophys. Res. Lett., 34, L21703, doi:10.1029/2007GL031223.

Giorgi, F., M. R. Marinucci, and G. Visconti (1990), Use of a limited-area model nested in a general circulation model for regional climate simulation over Europe, J. Geophys. Res., 95(D11), 18,413-18,431, doi:10.1029/90JD01642.

Habets, F., et al. (2008), The SAFRAN-ISBA-MODCOU hydrometeorological model applied over France, J. Geophys. Res., 113, D06113, doi:10.1029/2007JD008548.

Haylock, M. R., G. C. Cawley, C. Harpham, R. L. Wilby, and C. M. Goodess (2006), Downscaling heavy precipitation over the United Kingdom: A comparison of dynamical and statistical methods and their future scenarios, Int. J. Clim., 26, 1397-1415.

Ledoux, E., G. Girard, and J. P. Villeneuve (1984), Proposition d'un modèle couplé pour la simulation conjointe des écoulements de surface et des écoulements souterrains sur un bassin hydrologique, La Houille Blanche, l(2), 101-110.

Manabe, S., M. J. Spelman, and R. J. Stouffer (1992), Transient responses of a coupled ocean-atmosphere model to gradual changes of atmospheric CO2. Part II: Seasonal response, J. Clim., 5, 105-126.

Mearns, L. O., I. Bogardi, F. Giorgi, I. Matyasovszky, and M. Palecki (1999), Comparison of climate change scenarios generated from regional climate model experiments and statistical downscaling, J. Geophys. Res., 104(D6), 6603-6621, doi:10.1029/1998JD200042.

Meehl, G. A., et al. (2007a), Global climate projections, in Climate Change 2007: The Physical Science Basis. Contribution of Working Group I to the Fourth Assessment Report of the Intergovernmental Panel on Climate Change, edited by S. Solomon et al., Cambridge Univ. Press, Cambridge, U. K.

Meehl, G. A., C. Covey, T. Delworth, M. Latif, B. McAvaney, J. F. B. Mitchell, R. J. Stouffer, and K. E. Taylor (2007b), The WCRP CMIP3 multimodel data set: A new era in climate change research, Bull. Am. Meteorol. Sci., 88(9), doi:10.1175/BAMS-88-9-1383.

Noilhan, J., and S. Planton (1989), A simple parametrization of land surface processes for meteorological models, Mon. Weather Rev., 117, 536-549.

Quintana Segui, P., P. Le Moigne, Y. Durand, E. Martin, F. Habets, M. Baillon, L. Franchisteguy, S. Morel, and J. Noilhan (2008), Analysis of near-surface atmospheric variables: Validation of the SAFRAN analysis over France, J. Appl. Meteorol. Climatol., 47(1), 92-107.

Seneviratne, S. I., J. S. Pal, E. A. B. Eltahir, and C. Schär (2002), Summer dryness in a warmer climate: A process study with a regional climate model, Clim. Dyn., 20, 69-85.

Wilby, R. L., T. M. L. Wigley, D. Conway, P. D. Jones, B. C. Hewitson, J. Main, and D. S. Wilks (1998), Statistical downscaling of general circulation model output: A comparison of methods, Water Resour. Res., 34(11), 2995-3008, doi:10.1029/98WR02577. 
Wilby, R. L., S. P. Charles, E. Zorita, B. Timbal, P. Whetton, and L. O. Mearns (2004), Guidelines for use of climate scenarios developed from statistical downscaling methods, 27 pp., Data Distrib. Cent. of the Intergov. Panel on Clim. Change. (Available at http://ipcc-ddc.cru.uea.ac.uk)

J. Boé, Department of Atmospheric and Oceanic Sciences, UCLA, 7343 Math Sciences Building, 405 Hilgard Avenue, Los Angeles, CA 90095-

1565, USA. (boe@atmos.ucla.edu)
F. Habets, Centre de Géosciences, Équipe SHR, UMR Sisyphe 7619 , ENSMP, 35 rue St. honoré, F-77305 Fontainebleau, France.

E. Martin, Groupe d'études de l'Atmosphère Météorologique, Centre National de Recherches Météorologiques, Météo-France, CNRS, 42 avenue Gaspard Coriolis, F-31057 Toulouse CEDEX 1, France.

L. Terray, Global Change and Climate Modelling Project, URA 1875, CERFACS, CNRS, 42 avenue Gaspard Coriolis, F-31057 Toulouse CEDEX 1, France. 